\title{
Printed Crescent Shaped Monopole Antenna
}

\author{
R.Seetharaman, B.Shibi Bharat, R. \\ Sivaram, A.Vignesh, S.Vivek. \\ Department of Electronics and Communication \\ Engineering \\ College of Engineering Guindy \\ Anna University \\ Chennai 600025, India
}

\author{
M.Kannan \\ Department of Electronics Engineering \\ Madras Institute of Technology \\ Chrompet, Anna University \\ Chennai 600044, India
}

\begin{abstract}
This paper presents a printed crescent shaped antenna with a rectangular ground plane which belongs to the class of printed monopole antenna. The size of the antenna is very compact with an area of 15.75 square $\mathrm{cm}$. It exhibits the omnidirectional property of monopole antennas.
\end{abstract}

\section{General Terms}

Printed monopole antenna, UWB Specification.

\section{Keywords}

S- Parameter, Reflection Coefficient, VSWR, Directivity.

\section{INTRODUCTION}

Ultra Wide band (UWB) is a technology for the transmission of data using techniques which cause a spreading of the radio energy over a very wide frequency band, with a very low power spectral density. The low power spectral density provides better isolation from the other radio networks. This prevents cross interference problems among the radio networks. Furthermore, the high bandwidth enables high data throughput.

The technology can be used in various developing fields such as wireless USB, wireless high-definition video, nextgeneration Bluetooth, peer-to-peer connections.

UWB technology transmits message signal as pulses in time domain which occupies a large bandwidth in frequency domain. Hence the devices that would have antennas in them that can cover a wide range of frequencies are required. Moreover, since they are transmitted at low power, interference with other systems is effectively avoided. [6] Hence the antenna that would operate in an UWB device must be highly efficient so as to minimize the losses The size of the antenna plays a significant role in the portability and uses of the antenna. Hence a small and compact antenna is desirable. The combination of compactness and the omnidirectional pattern of monopole antennas is ideal.

Monopole antenna is a class of antenna where the antenna is mounted perpendicular to a ground plane. The antenna is usually a rod shaped metal conductor. The omnidirectional pattern is notable. It radiates power equally in all azimuthal directions perpendicular o the antenna.. However the radiated power differs with the elevation angle, and drops to zero at zenith on the antenna axis. If the thickness of the monopole antenna is reduced to that of a plane the resultant antennas are called planar antennas. These provide a larger bandwidth than their monopole counterparts but still these are not compact enough to be incorporated into smaller devices.[4]

Contrary to the monopole antennas, the micro strip patch antennas are compact and conformal but their resonant nature causes them to operate only in narrow bands. Many techniques have been propose to enhance the bandwidth of micro strip patch antennas but these would either increase the size of the antenna or upset the uniformity of the impedance match throughout the UWB band. [2]-[10]

Printed antennas have the design of patch antennas but envisage characteristics similar to that of a monopole antenna. These are small, conformal and have a wide impedance bandwidth. Many printed antennas have been discussed in literature.[12]

This paper discusses a crescent shaped printed antenna which belongs to a class of printed monopole antennas that meets the above UWB requirements. All the simulations are carried out using CST Microwave studios.

\section{DESIGN}

The Structural design of the proposed printed monopole [9] antenna fed by a $58 \Omega$ microstrip feed line is shown in Figure 1. It is printed on a Roger RT/ Duroid 5880(tm) substrate. This material is $1.6 \mathrm{~mm}$ thick, with a relative permittivity of 2.2 and a dielectric loss tangent of 0.0009 . The length of the patch is $\mathrm{L}=24.8 \mathrm{~mm}$ and width is $\mathrm{W}=15.3 \mathrm{~mm}$. The width of the microstrip feed line is fixed at $\mathrm{W} 2=4.9 \mathrm{~mm}$ for $58 \Omega$ impedance. A rectangle of cross section $3.2 \mathrm{~mm} \times 15 \mathrm{~mm}$ is connected between the patch and the $58 \Omega$ feed line for impedance matching (quarter wave transformer). The dimensions of the feed line are shown in Figure 2. 


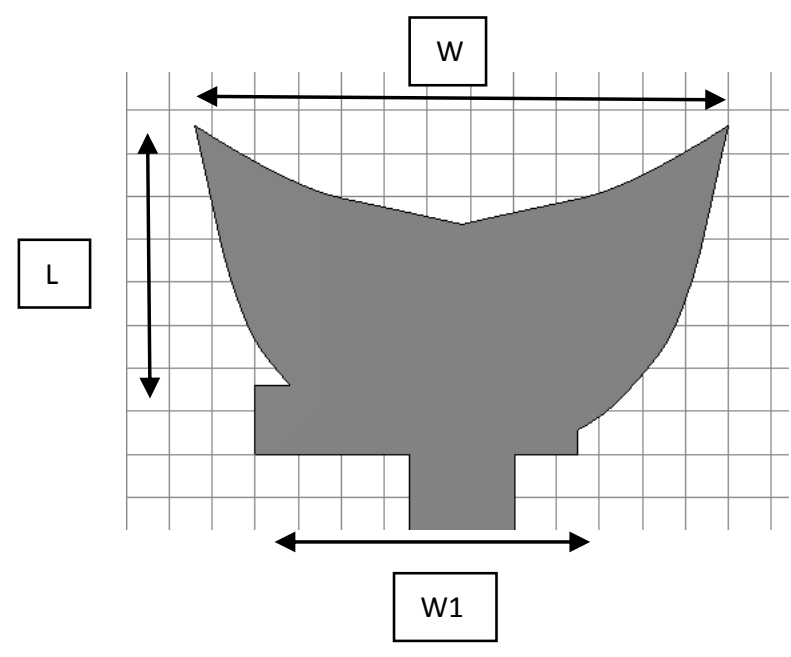

Fig. $1 \mathrm{~L}=15.3 \mathrm{~mm}, \mathrm{~W}=24.8 \mathrm{~mm}, \mathrm{~W} 1=15 \mathrm{~mm}$

Structure of crescent antenna $\mathrm{L}=15.3 \mathrm{~mm}, \mathrm{~W}=24.8 \mathrm{~mm}$. The substrate is of length $45 \mathrm{~mm}$ and width $35 \mathrm{~mm}$. The dimensions of the ground plane are $35 \mathrm{~mm} \times 15.4 \mathrm{~mm}$. The above dimensions of the antenna are for optimum performance got as a result of extensive simulations. Compared to center feed, it was found that for an offset feed (offset distance $\mathrm{f}=2.1 \mathrm{~mm}$ ) better impedance match is obtained.[6].

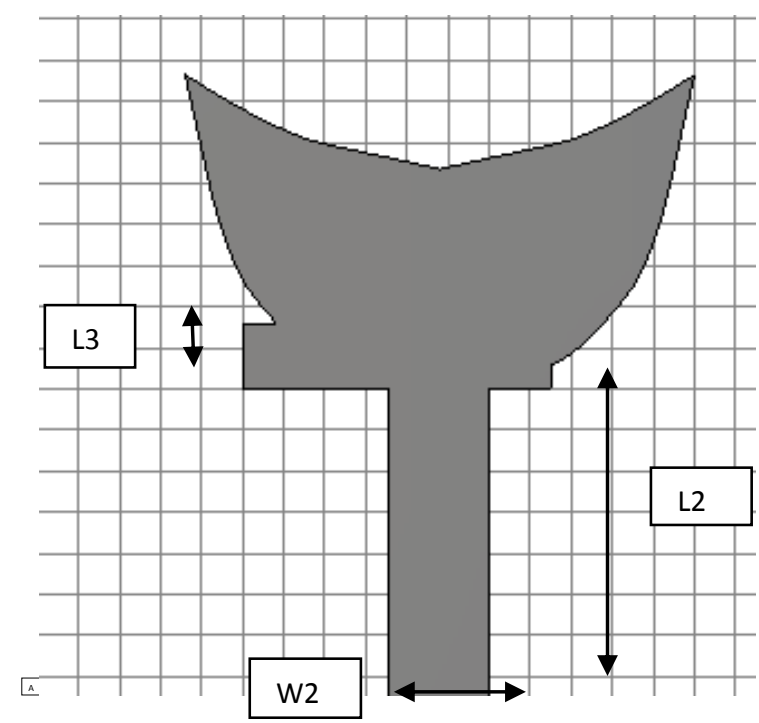

Fig.2 Feed dimensions $\mathrm{L} 2=15 \mathrm{~mm}, \mathrm{L3}=3.2 \mathrm{~mm}, \mathrm{~W} 2=$ 4.9mm.

\section{SCATTERING PARA}

The reflection coefficient( ) describes the amplitude or the intensity of the reflected wave relative to the incident wave. The scattering parameter is found by taking $10 \log$ of the reflection coefficient.

$\mathrm{S}$ parameter $=10 \log$

For an antenna to transmit $90 \%$ of the power in the output, the $\mathrm{S} 1$ parameter has to be below $-10 \mathrm{~dB}$. This antenna satisfies the $-10 \mathrm{~dB}$ constrain, over the range of $3.7 \mathrm{Ghz}$ to 14 Ghz. Hence, within this bandwidth, $90 \%$ power efficiency is obtained, suggesting the minimal loss of power.

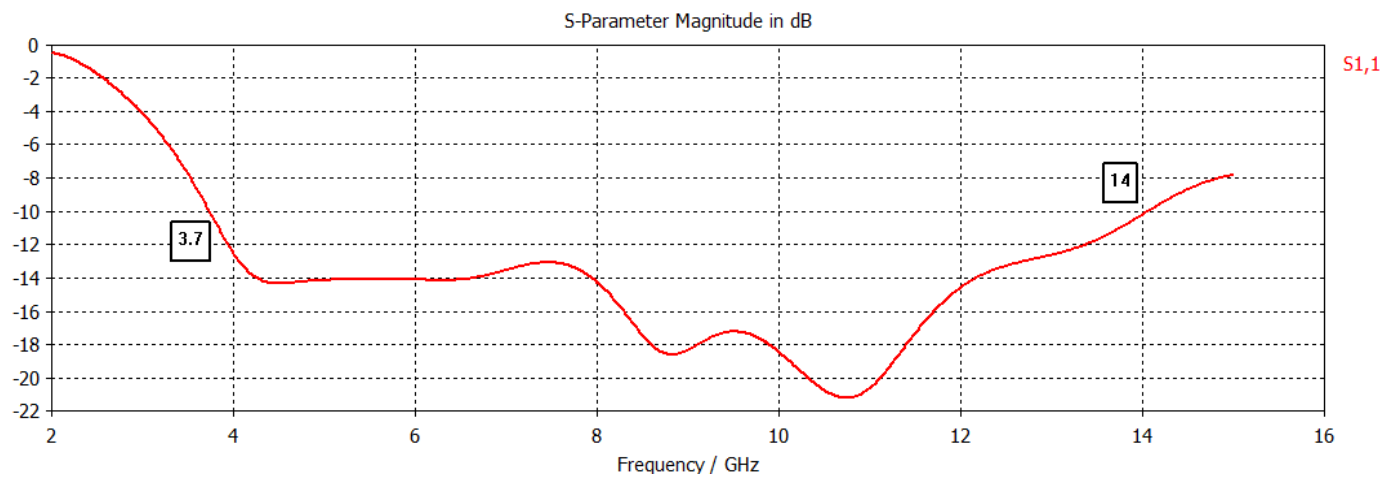

Fig 3 Reflection coefficient versus frequency

\section{VSWR}

VSWR (Voltage Standing wave ratio) is a function of the reflection coefficient, which describes the power reflected from the antenna. If the reflection coefficient is given by , then the VSWR is given by :

$$
V S W R=\frac{1+|\Gamma|}{1-|\Gamma|}
$$

The VSWR is a positive real number. If there is no power reflected from an ideal antenna, the VSWR would be 1 . Smaller value of the VSWR indicates that the antenna is 
properly matched to the transmission line and that the reflected power is negligible.

The proposed antenna satisfies the VSWR requirement of under 2. High values of VSWR result in a huge loss of transmitted power. If the reflected power is too huge, it may also damage the antenna. From the figure 4 and figure 5 , it is observed that the VSWR remains below 2, between the frequency ranges of $3.7 \mathrm{Ghz}$ to $14 \mathrm{Ghz}$.

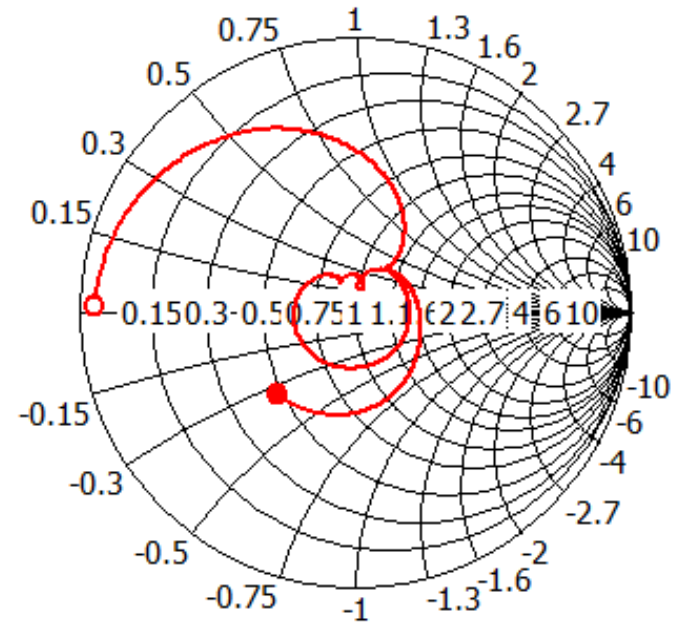

Fig 4. S-Parameter Smith Chart

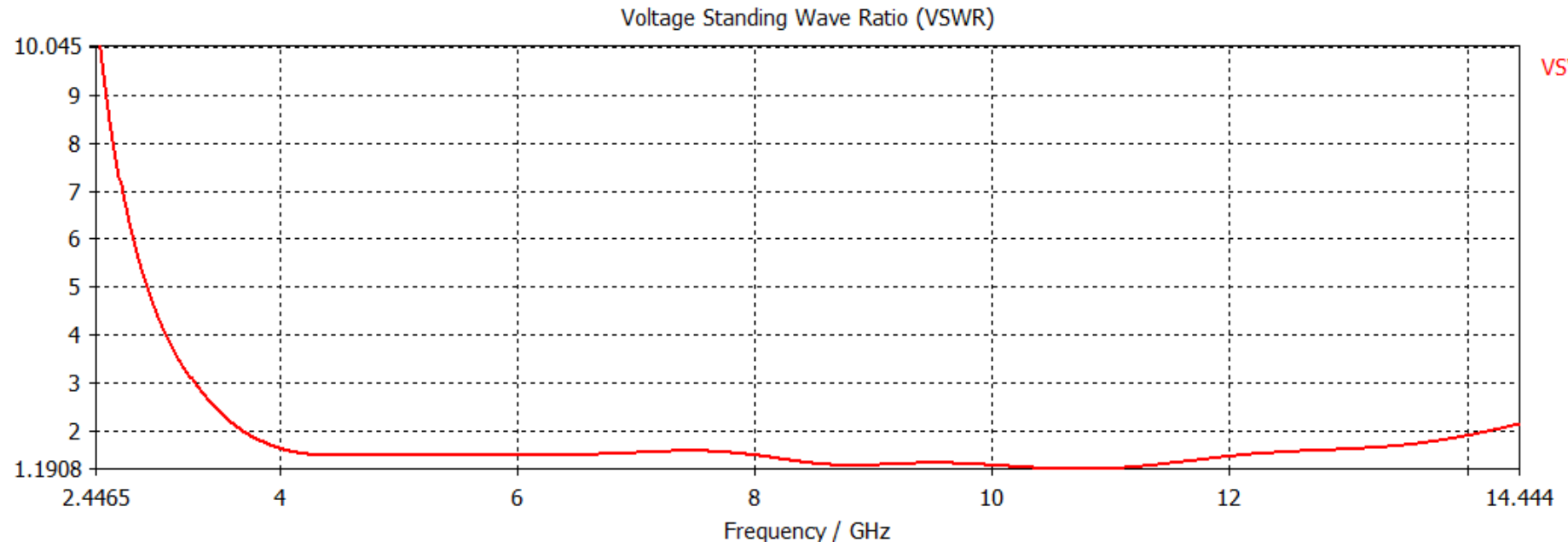

Fig 5 VSWR Plot

\section{DIRECTIVITY}

Directivity is a figure of merit for an antenna. It measures the power density the antenna radiates in the direction of its strongest emission, versus the power density radiated by an ideal isotropic radiator (which emits uniformly in all directions) radiating the same total power.

Directivity is an important measure because most emissions are intended to go in a particular direction or at least in a particular plane (horizontal or vertical); emissions in other directions or planes are wasteful (or worse).

Below are the representations of the directivity of the antenna for 3 frequencies: $5 \mathrm{GHz}, 7 \mathrm{GHz}$, and $9 \mathrm{GHz}$.

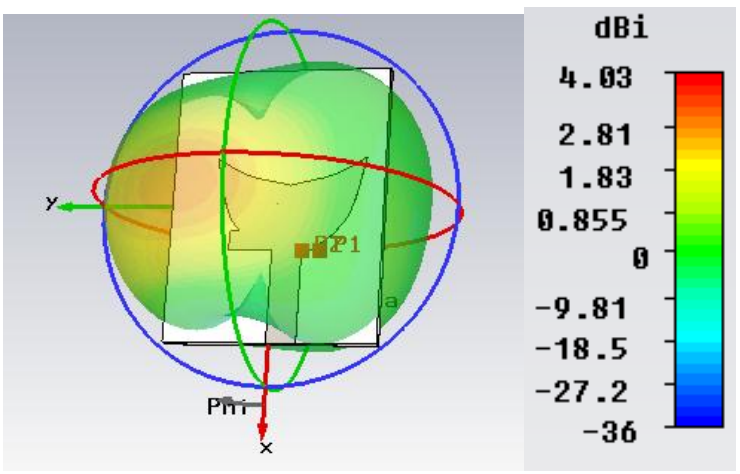

Fig.6 Directivity at $5 \mathrm{GHz}$ 


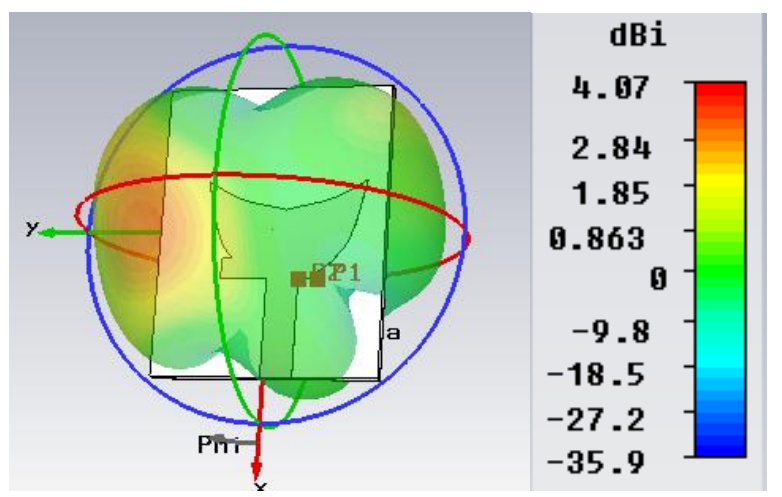

Fig.7 Directivity at $7 \mathrm{GHz}$

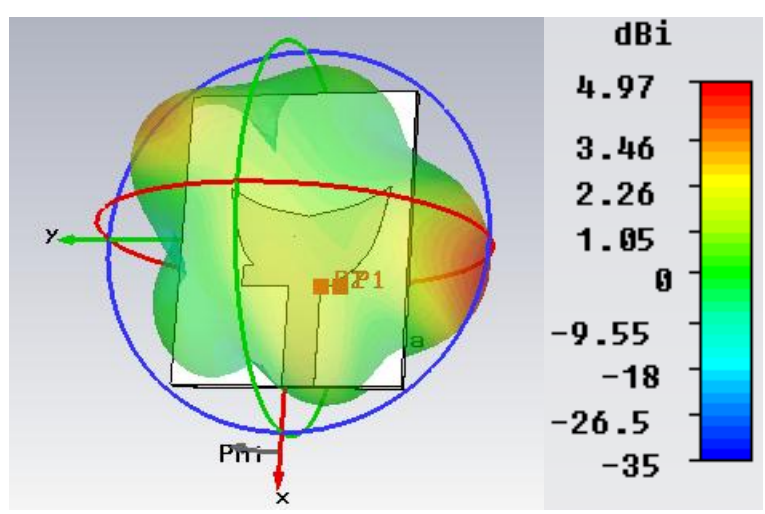

Fig.8 Directivity at $9 \mathrm{GHz}$

\section{CONCLUSION}

The printed crescent shaped antenna has been discussed as above. The analysis of various factors such as s1 parameters, VSWR and Gain has been performed. This compact antenna can be incorporated into smaller devices that operate in the UWB range. The developing UWB technology enables the utility of this antenna in various applications.

\section{REFERENCES}

[1] C.A.Balanis“ Antenna Theory" third edition john wiley, 2002

[2] R. Seetharaman , E. Gowtham Raj P. Geethanjali , S.Hariram, M.Kannan " Printed anchor shaped monopole Antenna" International Journal of 2012

[3] Reza Zaker, Changiz Ghobadi and Javad Nourinia, "Bandwidth Enhancement of Novel Compact Single and
Dual Band -Notched Printed Monopole Antenna with a pair of L-shaped slots ", IEEE Transactions on Antenna and Wave Propagation, Vol 57, No.12, December 2009.

[4] K. Gerorge Thomas and M.Sreenivasan, "A simple Ultra Wideband Planar Rectangular Printed Antenna with Band Dispensation", IEEE Transactions on Antenna and Wave Propagation, Vol 58, No.1, January 2010

[5] M.J. Ammann,Zhi Ning Chen, "Investigation on L-shaped lanar antennas", Radio Science, Vol.39, RS 2009, doi: 10. $1029 / 200 \mathrm{RS} 3$

[6] K.P.Ray "design Aspects of Printed Monopole Antennas for Ultra-wide band Applications" International Journal of Antennas and Propagation Vol 2008, Article ID 133858, Hindawi Publications.

[7] C.T.P. Song, Peter S. Hall and Ho GhafourShiraz,"Shorted Fractal Sierpinski Monopole Antenna", IEEE Transactions on Antenna and Wave Propagation, Vol 52, No.10, October 2004.

[8] Mohamed Nabil Srifi, Symon K Podilchak, Mohamed Essaidi, Yahia M.M. Antar, "Compact Disc Monopole Antennas for Current and Future Ultrawideband (UWB) Applications, IEEE Transactions on Antenna and Propagation, Vol 59, No.12, December 2011.

[9] Wen-Shan Chen, Kuang-Yuan $\mathrm{Ku}$ "Band-Rejected Design of the printed open slot Antenna for WLAN/WiMAX operation”, IEEE Transactions on Antenna and Wave Propagation, Vol 56, No.4, April 2008

[10] Rajender Singh, "Broadband Planar MonopoleAntennas" M.tech Credit Seminar Report, Electronic Systems group, Electrical Department, IIT Bombay, November 2003.

[11] I.J.Bahl and P.Bhartia, Microstrip Antennas, Artech House Dedham, MA, 1980.

[12] Rod.B. Waterhouse, S.D/ Targonski, D.M.Kokotoff, "Design and Performance of Small Printed Antennas" IEEE Transactions on Antenna and Propagation Vol.46, No.11, Nov 1998.

[13] Mohamed Nabil Srifi, Symon K Podilchak, Mohamed Essaidi, Yahia M.M. Antar, "Compact Disc Monopole Antennas for Current and Future Ultrawideband (UWB) Applications, IEEE Transactions on Antenna and Propagation, Vol 59, No.12, December 2011.

[14] S.Silver (Ed), Microwe Antenna Theory and Design, MIT, Radiation Lab. Series,Vol.12,McGraw-Hill, New Computer Applications (0975- 8887) Volume 43- No.5, April York, 1949 